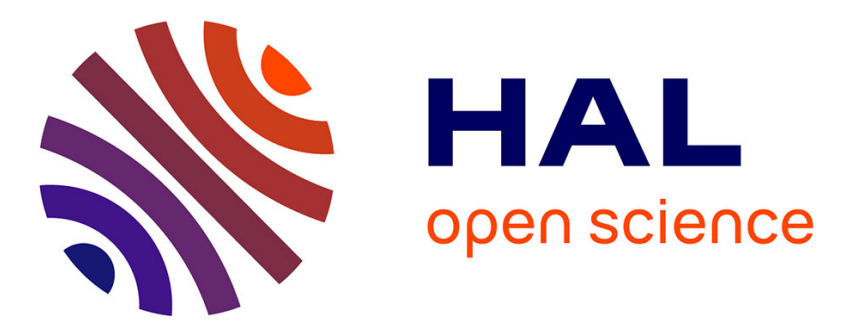

\title{
Mental time travel into the past and the future in healthy aged adults: an fMRI study.
}

Armelle Viard, Gaël Chételat, Karine Lebreton, Béatrice Desgranges, Brigitte Landeau, Vincent de La Sayette, Francis Eustache, Pascale Piolino

\section{- To cite this version:}

Armelle Viard, Gaël Chételat, Karine Lebreton, Béatrice Desgranges, Brigitte Landeau, et al.. Mental time travel into the past and the future in healthy aged adults: an fMRI study.: Mental time travel into the past and the future. Brain and Cognition, 2011, 75 (1), pp.1-9. 10.1016/j.bandc.2010.10.009 . inserm-00647097

\section{HAL Id: inserm-00647097 https://www.hal.inserm.fr/inserm-00647097}

Submitted on 1 Dec 2011

HAL is a multi-disciplinary open access archive for the deposit and dissemination of scientific research documents, whether they are published or not. The documents may come from teaching and research institutions in France or abroad, or from public or private research centers.
L'archive ouverte pluridisciplinaire HAL, est destinée au dépôt et à la diffusion de documents scientifiques de niveau recherche, publiés ou non, émanant des établissements d'enseignement et de recherche français ou étrangers, des laboratoires publics ou privés. 
Mental time travel into the past and the future in healthy aged adults: an fMRI study

Armelle Viard ${ }^{1 *}$, Gaël Chételat ${ }^{1}$, Karine Lebreton $^{1}$, Béatrice Desgranges ${ }^{1}$, Brigitte Landeau ${ }^{1}$, Vincent de La Sayette ${ }^{1}$, Francis Eustache ${ }^{1}$, Pascale Piolino ${ }^{1,2,3 *}$

${ }^{1}$ Inserm-EPHE-Université de Caen/Basse-Normandie, Unité U923, GIP Cyceron, CHU Côte de Nacre, Caen, France.

${ }^{2}$ Université Paris Descartes, Institut de Psychologie, Paris, France

${ }^{3}$ CNRS, UMR 8189, Laboratoire Psychologie et Neurosciences Cognitives, Paris, France

* Correspondance to: Dr. Armelle Viard, Inserm-EPHE-Université de Caen/BasseNormandie, Unité U923, GIP CYCERON, Bd Becquerel BP 5229, F-14074 Caen Cedex, France. Tél:+33(0)2 $31 \quad 47 \quad 01 \quad 07$ Fax:+33(0)2 $31 \quad 47 \quad 02$ 22. E-mail addresses: viard@cyceron.fr, pascale.piolino@parisdescartes.fr

Abbreviated title : Mental time travel into the past and the future.

Number of text pages: 22

Number of tables: 4

Number of figures: 1

Key words : autobiographical memory, episodic memory, future thinking, hippocampus, fMRI. 


\begin{abstract}
Remembering the past and envisioning the future rely on episodic memory which enables mental time travel. Studies in young adults indicate that past and future thinking share common cognitive and neural underpinnings. No imaging data is yet available in healthy aged subjects. Using fMRI, we scanned older subjects while they remembered personal events (PP: last 12 months) or envisioned future plans (FP: next 12 months). Behaviorally, both timeperiods were comparable in terms of visual search strategy, emotion, frequency of rehearsal and recency of the last evocation. However, PP were more episodic, engaged a higher state of autonoetic consciousness and mental visual images were clearer and more numerous than FP. Neuroimaging results revealed a common network of activation (posterior cingulate cortex, precuneus, prefrontal cortex, hippocampus) reflecting the use of similar cognitive processes. Furthermore, the episodic nature of PP depended on hippocampal and visuo-spatial activations (occipital and angular gyri), while, for FP, it depended on the inferior frontal and lateral temporal gyri, involved in semantic memory retrieval. The common neural network and behavior suggests that healthy aged subjects thought about their future prospects in the past. The contribution of retrospective thinking into the future that engages the same network as the one recruited when remembering the past is discussed. Within this network, differential recruitment of specific areas highlights the episodic distinction between past and future mental time travel.
\end{abstract}




\section{Introduction}

Episodic memory is the only memory system that allows individuals to mentally travel in subjective time, into either the past or the future (Tulving, 2002, 2005). This ability depends on autonoetic consciousness which mediates an individual's awareness of his or her existence and identity in subjective time. Converging lines of evidence from different fields of research indicate that remembering the past or envisioning the future share common cognitive and neural underpinnings. First, developmental studies suggest that the level of awareness for episodic remembering and the ability to identify with future interests develops around ages three to four (Wheeler et al., 1997; Atance \& O’Neil, 2001; Levine, 2004). Second, agerelated changes seem to affect similarly the quality of past and future mental evocations, with older adults generating fewer details for past and future events compared to younger adults (Addis et al., 2008). Third, neuropsychological case studies have shown that patients with hippocampal lesions have difficulties in remembering their personal past, but also in foreseeing their personal future (patient KC, Tulving, 1985; patient DB, Klein et al., 2002; Hassabis et al., 2007a), their productions lacking in episodic details compared to age-matched controls (Addis et al., 2009; Gamboz et al., 2010). Fourth, certain phenomenological characteristics similarly affect past and future mental thinking, such as positive emotional valence and temporally close events which are associated with a stronger feeling of reexperiencing or pre-experiencing (D’Argembeau \& Van der Linden, 2004, 2006; Addis et al., 2008; Gamboz et al., in press). Most recently, a growing number of neuroimaging studies detect a common neural network when thinking about the past or the future (Buckner \& Carroll, 2007; Schacter and Addis, 2007; Hassabis \& Maguire, 2007, 2009).

Main results from the neuroimaging literature indicate a striking overlap between past and future thinking, especially during the elaboration phase, attributable to common cognitive processes (Okuda et al., 2003; Addis et al., 2007; Szpunar et al., 2007; Hassabis et al., 2007b; 
D'Argembeau et al., 2008; Botzung et al., 2008; Spreng \& Grady, 2010; Weiler et al., 2010). Indeed, past and future representations are intimately linked to the self, mediated, in particular, by the medial prefrontal cortex (Northoff \& Bermpohl, 2004; Gusnard et al., 2001; Kelley et al., 2002). Both past and future event constructions are strongly dependent on visual mental imagery, which increases the number of details retrieved and the subjective sense of remembering (Greenberg \& Rubin, 2003), attributable to activity in the precuneus (Cavanna \& Trimble, 2006; Fletcher et al., 1995). The ability to visualize complex spatial scenes is also necessary to mentally construct past or future events, reliant on activity in the posterior cingulate cortex (Hassabis et al., 2007b; Szpunar et al., 2007, 2009). Past and future representations require the binding of details into a coherent event mediated by the medial temporal lobe, including the hippocampus (Eichenbaum, 2001). Its role in recombining details of past events during episodic autobiographical recollection has been shown previously (Viard et al., 2007, 2010) and extended to novel integration of details into coherent future events (Addis et al., 2007; Hassabis et al., 2007b; Andrews-Hanna et al., 2010).

Different hypotheses have been proposed to account for this common core network. On one hand, Buckner and Carroll (2007) speculate that self-projection (i.e., the ability to mentally project oneself from the immediate present into a simulation of another time, place or perspective) may underlie the common brain network shared by past and future thinking, and other cognitive domains (theory of mind and navigation). A complementary idea, the "constructive episodic simulation hypothesis" formulated by Schacter and Addis (2007), posits that past and future events build on similar information stored in episodic memory and rely on similar cognitive processes (i.e., self-referential processing, imagery and flexible recombination of stored details). Novel events could, hence, be generated by reassembling and flexibly recombining stored event details. On the other hand, Hassabis and Maguire (2007) show that imagination, which may not depend on self-related nor on time-related 
processes, relies on the same brain regions. They propose that scene construction (i.e., the process of mentally generating and maintaining a complex and coherent scene or event) may better explain the commonalities in the brain areas engaged.

Although sharing remarkable similarities, both at the cognitive and neural level, past and future events obviously differ in that past events represent real experiences, while future events are based on predictions and estimations, reflected by differences at the phenomenological level. Past events contain more visual and other sensory details than future events (D’Argembeau \& Van der Linden, 2004, 2006; Addis et al., 2008; Anderson \& Dewhurst, 2009), in line with the "reality monitoring framework" which posits that memories of real events include more sensory and contextual details than memories for imagined events (Johnson \& Raye, 1981; Johnson, 1991; Conway et al., 2002). Moreover, participants experience past events with a clearer representation of contextual (spatial and temporal) information, with a more coherent story, and perceive the event more from a field perspective compared to future events (D'Argembeau \& Van der Linden, 2006). Conversely, future simulations are rated as being more positive and personally significant compared to past events, indicating the existence of an optimistic bias towards the future (D'Argembeau \& Van der Linden, 2006; Sharot et al., 2007; Addis et al., 2008). Past and future evocations also change as people get older and, although all age groups produce intentions, those of older people take place closer to the present, become less frequent as time from present increases (Spreng \& Levine, 2006) and tend to contain less episodic details than younger adults (Addis et al., 2008). Up to now, no study has yet compared brain activation during past and future thinking in older people.

In this study, we used functional imaging to examine brain activations while projecting into the past or the future, in an older population. In the scanner, upon presentation of a cuephrase prompting a specific past or future event (obtained by questioning a close family 
member), participants were asked to mentally recall specific events from the past 12 months and specific plans they intended to pursue in the next 12 months. Our first aim was to assess whether past and future thinking shared common neural bases in healthy aged people. Our second aim was to determine, if a neural overlap was observed, how it could be explained by the phenomenological quality of the events produced. Debriefing was particularly thorough as past and future mental evocations were rated on a five-point episodic scale, as well as on the mental strategy used, the quality and number of mental images retrieved, perspective taken, emotional intensity and valence. To test the idea of mental time travel in subjective time and examine the influence of retrospective thinking, additional scales not previously used in neuroimaging studies examining the future evaluated the state of consciousness, frequency of rehearsal and recency of last evocation.

\section{Materials and methods}

Participants

Twelve right-handed (as measured by the Edinburgh handedness inventory) healthy females (mean age $\pm \mathrm{SD}=67.2 \pm 5.2$ years; ranging from 60 to 75 years old) with no history of psychiatric or neurological disorder were recruited through a university, a retirement association or a newspaper advertisement. To obtain a homogeneous group, we recruited only females. Indeed, gender-related differences have been shown to affect both the behavioural (Goddard et al., 2005) and neural levels (Piefke \& Fink, 2005) of autobiographical recollection. The study was approved by the Regional Ethics Committee and written informed consent was obtained from all subjects prior to their participation in the study. Participants had no abnormality on their $\mathrm{T}_{1}$-weighted high-resolution magnetic resonance imaging (MRI). They underwent a battery of neuropsychological tests to assess their cognitive abilities and all performed in the normal range (see Viard et al., 2007, for a full description). Each participant resided at home and all were active in cultural pursuits, continuing education or with 
responsibilities in diverse associations. The present data were obtained as part of a broader experiment exploring five past periods previously published (Viard et al., 2007, 2010). Here, we present new results concerning the future period (next 12 months) and compare them to the mirroring past period (i.e., past 12 months).

\section{Task and experimental design}

A few weeks before the scanning session, a close family member was interviewed on the participant's specific life events and future plans. On the day of the scanning session, a training period preceded the functional scan which was followed by a debriefing. Personal sentence-cues were elaborated from the family member's prior interview and cues were visually presented in white on a black background, using Superlab software (3.0 version, Cedrus). Upon presentation of the visual cue, participants were instructed to recall or envision a specific detailed event, unique in time and space, that had either occurred in the past 12 months (past period, PP) or was scheduled in the next 12 months (future period, FP). For both past and future events, they were asked to experience the event with as much details as possible. The functional runs, one per time-period, were composed of five experimental and five control blocks, randomly intermixed across subjects. In the experimental condition, participants viewed sentence-cues ( 5 seconds) followed by a blank screen (19 seconds) during which they had to mentally experience the corresponding specific personal event (e.g., past: my grandson's last birthday party; future: my fifty-third wedding anniversary). Since they could start their mental evocation while the cue was still on the screen, the maximum retrieval time was 24 seconds per block. They were asked to press on a button as soon as they gained access to the prompted event.

In the control condition, participants were asked to detect the presence of two consecutive letters ("mb") in a pseudo-word of six letters (for example, "speugr" or "mbieha") and were instructed to press on a button when "mb" was present in the pseudo-word (i.e., target word). 
This low-level task was chosen as a baseline condition in order to control for reading operations, mental processing of visual cues and motor processing, common to both experimental and control tasks. Five pseudo-words were presented in each control block (1 second for cue presentation, followed by 3.8 seconds for the response) and one out of the five was a target word. Thus, each control block lasted 24 seconds (i.e., 5 x $(1+3.8)$ seconds). The position of target words was randomly intermixed across blocks. Overall, in both experimental and control blocks, cue presentation (i.e., reading) lasted five seconds and only one key-press was required per block.

Following the scanning session, a debriefing took place in which participants verbally described all events retrieved in the scanner and rated them on behavioral scales. Such a procedure is widely used in neuroimaging studies of autobiographical memory and proves to be a successful method to evaluate the nature of the events recalled in the scanner (Maguire $\&$ Frith, 2003; Gilboa et al., 2004; Rekkas \& Constable, 2005; Steinvorth et al., 2006; Gardini et al., 2006; Nadel et al., 2007; Daselaar et al., 2008; Piolino et al., 2004, 2008; Viard et al., 2007, 2010). First, the episodic nature of the events was rated by the investigator on a fivepoint scale taking into account the specificity of the content (single or repeated event), the spatiotemporal situation and the presence of details (perceptions, thoughts, feelings) (Piolino et al., 2004; Viard et al., 2007, 2010). This scale not only distinguishes specific from generic events, but also separates episodic (specific without any details, but situated in time and space) from strictly episodic events (specific with sensory details situated in time and space). A specific event with sensory details situated in time and space was given a score of 4 . A specific event without any details but situated in time and space was scored 3. A repeated or extended event was scored 2 if it was situated in time and space or 1 if it was not. An absence of event, or only general information about a theme, was scored 0 . The strictly episodic score 
(EM) was recorded per time-period, taking into account the number of specific and detailed memories scoring 4 (maximum per time-period 4 x $5=20$ ).

Second, in order to specify the different aspects of the recollective experience, participants were asked to rate their evocations on several analogical scales (10-cm lines; subjective measurement) known to be crucial to control the degree of episodic re-experiencing (Viard et al., 2007, 2010; Piolino et al., 2004, 2009). These scales evaluated visual mental imagery, emotional intensity and valence, state of consciousness, frequency of rehearsal and recency of the last evocation. More specifically, it has previously been shown that visual mental imagery increases the recall of specific details (Dewhurst \& Conway, 1994; Brewer, 1996; Rubin et al., 2003). Thus, participants had to rate the mental strategy used during retrieval (verbal or visual), the mental image quality, the number of mental images retrieved and the point of view (field or observer; Nigro \& Neisser, 1983). In the "field" perspective, mental images represent the scene from the point of view from which it was originally experienced, while in the “observer" perspective, mental images represent the original scene as an external observer might have seen it. The "field" perspective characterizes episodic recollection (Crawley \& French, 2005; Piolino et al., 2006). Emotion is also an important phenomenological characteristic of vivid autobiographical memories (Brewer, 1988; Dolan et al., 2000) and affects both past and future mental evocations (Addis et al., 2007; Hassabis et al., 2007b; D’Argembeau et al., 2008; Sharot et al., 2007; Weiler et al., 2010). Participants were asked to rate their productions on scales measuring emotional intensity and valence.

We added other scales not previously used in neuroimaging studies examining the future to further explore the phenomenology of past and future mental evocations and more specially the involvement of retrospective thinking into the future. The state of consciousness can be distinguished by the Remember/Know $(\mathrm{R} / \mathrm{K})$ procedure which has been previously used both in laboratory (Gardiner, 2001 for a review) or real-world (Piolino et al., 2009 for a review) 
investigations of episodic memory. The autonoetic state $(\mathrm{R})$ characterizes episodic memory, while the noetic state (K) characterizes semantic memory (Tulving, 1985; Gardiner, 1988; Gardiner \& Java, 1993). Unlike the "knowing" state, the "remembering" state is characterized by phenomenal elements associated with the recall of specific events (visual images, sensations, feelings). For the future, an $\mathrm{R}$ response indicates that subjects remember to have thought about their plan via a feeling of recollection. Participants were asked to rate their productions on a scale measuring the state of consciousness between the autonoetic and noetic states. Note that four subjects were uncomfortable to rate their state of consciousness relative to the future period, hence analyses for this scale were run over eight subjects. Several authors have demonstrated the influence of repetition on autobiographical memories (talking or thinking about the same event), leading to a reinforcement of specific details (Conway \& Dewhurst, 1995) or to a decontextualization or semantization of memories (Brewer, 1986; Linton, 1986, 1988; Cermak, 1984). We controlled for recent reactivation by evaluating if past or future events had been thought about recently or not, using two analogical scales. The frequency of rehearsal evaluates how frequently each event was rehearsed prior to scanning, if it was the case, and the recency of the last evocation evaluates when each event was last evoked.

\section{fMRI data acquisition}

A blocked functional MRI design was used. Lying in the scanner, participants viewed the display via a mirror to an active matrix video projector. Stimulus onset was synchronized with the acquisition of the first slice. Anatomical and functional MRIs were acquired on a General Electrics Signa 1.5 tesla MRI scanner (GE, BUC, France). First, a high-resolution T1weighted MRI scan (T1-MRI) was acquired with a three-dimensional inversion recovery spoiled gradient echo sequence (matrix size $=256 \times 256 \times 128$; slice thickness $=1.5 \mathrm{~mm}$ ). Second, a proton density/T2-weighted MRI scan (PD-MRI, T2-MRI) was acquired with 32 
axial slices covering the entire brain and the superior part of the cerebellum (slice thickness $=$ $3.8 \mathrm{~mm}$ ). Finally, functional images were acquired with echo planar imaging blood oxygen level dependent $(\mathrm{BOLD})$ sequence (repetition time $=6 \mathrm{~s}$, echo time $=60 \mathrm{~ms}$, flip angle $=90^{\circ}$, matrix size $=64 \times 64 \times 32,50$ volumes, $3.8-\mathrm{mm}$-thick slices) covering the same field of view as the T2-MRI acquisition.

Construction of an old-adult template

Using voxel-based morphometry (VBM; Good et al., 2001), each individual T1-MRIs were segmented according to the unified segmentation procedure (Ashburner and Friston, 2005) with spatial normalization included. Mean templates were calculated based on the individual segmented and normalized T1-MRIs, creating three separate old-adult templates according to tissue type (i.e., grey and white matters, cerebro-spinal fluid) which were then spatially smoothed using an 8-mm FWHM Gaussian kernel. Coordinates are reported in the MNI stereotaxic space.

Functional image pre-processing

Functional images were processed and analyzed using the Statistical Parametric Mapping software (SPM5; Wellcome Department of Cognitive Neurology, London, United Kingdom; http://www.fil.ion.ucl.ac.uk/spml). The first six volumes of the functional acquisition were discarded, allowing for signal stabilization, and differences in slice acquisition timing were corrected. Images were realigned to correct for interscan movement with the creation of resliced mean functional volumes (mean-fMRI). For inter-modalities registration, rigid registration matrices (mean-fMRI onto T2-MRI, PD-MRI onto T1-MRI, T1-MRI onto the old-adult template) were computed, combined and then applied to fMRI volumes. Individual T1-MRIs were then segmented using the old-adult templates as priors (obtained previously, one for each tissue type; see above) and normalized. In order to set the fMRI volumes into our 
old-adult space, functional MRI images were resampled using the normalization parameters obtained in the segmentation step. Finally, data were spatially smoothed with an $8-\mathrm{mm}^{3}$ FWHM Gaussian kernel.

Behavioral data analysis

A repeated measure analysis of variance (ANOVA) was applied to behavioral scores, followed by post hoc tests [protected least significant differences (PLSD) Fisher], to examine the influence of the time-period. To better delineate what best characterized episodicity of past and future evocations (i.e., events scored 4, EM), stepwise regression analyses were conducted to study the relationships between the strictly episodic score (EM) and the analogical scales.

\section{fMRI data analysis}

In the basic model, fMRI time series were modelled by a general linear model (GLM) including separate regressors for each of the experimental (past and future periods) and control conditions using SPM5. All regressors were convolved with the canonical hemodynamic response function $(\mathrm{HRF})$. Data were high-pass filtered (cut-off period $=96 \mathrm{~s}$ ). Coefficients for each regressor were estimated for each participant using maximum likelihood estimates to account for serial correlations in the data. At the first level, linear contrasts of the parameter estimates for each "experimental" regressor of interest were calculated for each participant, subtracting the corresponding "control" regressor (resulting in "period minus control" contrasts). These contrasts were then brought to the second level random effects analysis, across all subjects, applying the paired t-test model of SPM5. First, a conjunction analysis was performed to detect cerebral regions commonly activated by both past and future time-periods. In this test, all the comparisons in the conjunction are individually significant which corresponds to the valid test for a "logical AND" (Nichols et al., 2005). Second, 
subtraction analyses were computed to determine which regions were differentially activated when comparing both time-periods. We report activations at an uncorrected statistical threshold of $\mathrm{p}<0.001, \mathrm{k}>15$ voxels. Coordinates of brain regions are reported in the MNI space.

In order to determine which brain region best explained the episodic nature of past and future thinking (as assessed by the EM score), voxel-based regression analyses were carried out for past and future periods separately between the EM score and whole brain activations. For each time-period (past or future), voxel-by-voxel positive regression analyses were launched across the 12 subjects between the EM scores and contrast images of the corresponding time-period obtained at the first-level (see above). The threshold was set at $\mathrm{p}<$ 0.005 uncorrected for multiple comparisons, $\mathrm{k}>15$ voxels.

\section{Results}

Behavioral results

Behavioral results indicate that events from both past and future periods were comparable in terms of the strategy used (massively visual) and viewpoint of mental images (principally field), emotional intensity and valence, frequency of rehearsal and recency of the last evocation. In contrast, past memories were rated as more episodic (based on the EM score), were recalled with a higher state of autonoetic consciousness and had a better image quality and a higher number of mental images compared to future events (see Table 1). Final results of the forward stepwise regression analysis showed that the best predictors for the strictly episodic score (EM) when recalling past events were mental visual image quality (explaining $49.2 \%$ of the variance) and a field perspective (explaining $21 \%$ of the variance). The best predictor for the EM score when envisioning future events was a field perspective (explaining $22 \%$ of the variance). 
fMRI results

\section{Conjunction analysis}

The conjunction analysis revealed a bilateral parieto-fronto-temporal network commonly active when recalling past or future events (see Table 2 and Figure 1), including the posterior cingulate cortex (BAs 23, 30), precuneus (BA 7), angular gyrus (BA 39), middle (BAs 8, 6, 9), superior (BAs 8) and inferior (BA 47) frontal gyri, superior (BAs 38, 22) and middle (BA 21) temporal gyri, left hippocampus and parahippocampal gyrus (BA 36), a visuo-spatial region (calcarine sulcus, BA 17), thalamus and cerebellum. Activation in the medial prefrontal cortex (BAs 32, 10) and right hippocampus appeared subthreshold (at $\mathrm{p}_{\text {unc }}<0.005$ ).

\section{Subtraction analyses}

Subtraction analyses revealed mainly higher parietal activation for future compared to past events (see Table 3), localized in the inferior (BA 40) and superior (BA 7) parietal gyri, angular gyrus (BA 39) and cerebellar activation extending into visuo-spatial areas (lingual gyrus, BA 18). No difference appeared for past compared to future events.

\section{Regression analyses}

Results of the regression analyses between the episodic score (EM) and brain activations were all positive and showed that, for the past, EM depended on activation in the right middle occipital gyrus (BA 19), right hippocampus, left angular gyrus (BA 39), posterior cingulate cortex (BA 30), thalamus and insula (see Table 4). For the future, EM depended on activation in the left inferior frontal gyrus (BAs 45, 44), bilateral superior temporal gyrus (BAs 42, 21, 22), precuneus (BA 31) and thalamus.

\section{Discussion}

We used fMRI to explore the cerebral structures recruited by healthy aged subjects when thinking about personal specific events from the past 12 months (past) and the next 12 months 
(future), in an attempt to answer two main questions. First, do past and future thinking share a common neural basis in healthy aged adults? Second, if a neural overlap is present, how can it be explained by the phenomenological quality of the events produced? Neuroimaging results revealed a bilateral parieto-fronto-temporal network, including medial temporal areas, commonly active when recalling past or future events, suggesting that past and future thinking build on the same cerebral underpinnings, as found in the literature on younger adults (see introduction). Original behavioral measures helped us further understand these neural commonalities indicating that past and future events were comparable in terms of the frequency of rehearsal and recency of the last evocation. Past and future events were also comparable on certain phenomenological qualities (mental visual strategy, emotional intensity and valence). However, most strikingly, past events were more episodic (i.e., contained more details), were retrieved with a higher state of autonoetic consciousness and mental visual images were clearer and more numerous than for future events. Subtraction analyses mainly revealed hyperactivation in the posterior parietal cortex for future events compared to past events. When investigating further the episodic quality of both types of events, regressions analyses revealed that the episodic nature of past memories was particularly dependent on activation in the right hippocampus and visuo-spatial areas (occipital and angular gyri, posterior cingulate cortex), while the episodic nature of future thoughts depended mainly on inferior frontal and superior temporal areas. We will, first, discuss how the common neural network between past and future thinking can be explained by common cognitive processes and, second, discuss how the episodic distinction between past and future thinking can be linked to a differential engagement of specific areas within this common neural network.

Cognitive and neural overlap underlying mental time travel

Activation was detected in the posterior cingulate cortex, precuneus and medial prefrontal cortex (albeit subthreshold) for both past and future events, regions belonging to the cortical 
midline structures (CMS) which play a role in self-referential processes (Northoff \& Bermpohl, 2004) and are hypothesized to mediate self-projection in time, whether in the past or in the future (Hassabis et al., 2007b; Addis et al., 2007; Szpunar et al., 2007, 2009). The precuneus is also associated with access to sensory-perceptual details via its role in visual mental imagery and the posterior cingulate cortex is recruited when mentally visualizing complex spatial contexts (see introduction). This interpretation is further confirmed by our behavioral data which indicate that participants preferentially used a visual strategy to retrieve past and future events. An overlap between both time-periods was also detected in the occipital cortex known for its role in visuo-spatial processes. It is likely that to envision future events, participants reactivated previously experienced visuo-spatial contexts and placed their mental images of future events in familiar contexts (Szpunar et al., 2007, 2009; D’Argembeau \& Van der Linden, 2004, 2006; Schacter and Addis, 2007). Our behavioral data further indicate that mental images were visualized from a field perspective for both time-periods, indicating that participants projected themselves in time and visualized past and future events as if they were re-experiencing or pre-experiencing them from a first person perspective. This perspective is known to be closely connected to emotional context and current self (Nigro \& Neisser, 1983; Libby \& Eibach, 2002).

Activation in the middle and superior frontal gyri was detected for both past and future thinking, in line with other studies in younger adults (Okuda et al., 2003; Addis et al., 2007; Botzung et al., 2008; Abraham et al., 2008; Weiler et al., 2010). Left-lateralized inferior frontal gyrus (or ventrolateral prefrontal cortex in another terminology; BA 47) is involved in the controlled retrieval of semantic information (Raposo et al., 2009; Conway et al., 2003; for review, Badre and Wagner, 2007) and in more elaborate cue-specification strategies (Petrides, 2002) necessary to retrieve episodic AMs (Piolino et al., 2008) and past and future events (Addis et al., 2007). The middle frontal gyrus (or dorsolateral prefrontal cortex in another 
terminology; BAs 8,6) would help to manipulate the products of retrieval in working memory (Cabeza \& St Jacques, 2007) and could also have a role in the recollection of the temporal context of episodic core information for both past and future events (Botzung et al., 2008).

Activation in the hippocampus was also detected for both past and future thinking. Much evidence links the hippocampus to episodic autobiographical memory retrieval (for reviews, Maguire, 2001; Svoboda et al., 2006; Cabeza \& St Jacques, 2007; Piolino et al., 2009). Here, we show that its role extends to the anticipation of future events in older subjects, as found in the literature on younger adults (Okuda et al., 2003; Addis et al., 2007; Hassabis et al., 2007b; Botzung et al., 2008; Abraham et al., 2008). The hippocampus plays a critical role in binding disparate details together (see introduction) necessary to construct coherent scenes of the past and the future (Hassabis et al., 2007b; Addis et al., 2007; Spreng \& Grady, 2010), ability which is strongly impaired in hippocampally-lesioned patients (Tulving, 1985; Klein et al., 2002; Hassabis et al., 2007a). For the past, it would serve to reactivate and reintegrate details of a memory bound together at encoding and, for the future, hippocampal activity would reflect the integration of disparate details into a novel future event (Addis et al., 2007).

How can we explain this common neural network? Past and future thinking both depend on the episodic memory system which enables mental time travel (Tulving, 2002). As stated above, it is likely that aspects of previously experienced events are used to envision the future, hence explaining the neural overlap between both processes. The present study offers an additional explanation. In our experiment, participants were asked to project themselves in a particular moment of future plans they intended to fulfill in the next 12 months. Although prior to the experiment, they had not thought or talked in detail about specific events concerning these future prospects, these projects were nonetheless planned in the past (see also other studies where participants thought about future events which were planned in the past: Okuda et al., 2003; Botzung et al., 2008; Weiler et al., 2010; Peters \& Büchel, 2010). 
Accordingly, behavioral data indicate that past and future events were comparable in terms of frequency of rehearsal and recency of the last evocation. Thus, another possible explanation for the common neural network observed when thinking about the past or the future is that when planning an event beforehand, a future event automatically adopts a retrospective form and thinking about it reactivates the same network as the one recruited when remembering the past. Our results highlight the neural network recruited by the retrospective component of future thinking as suggested by Schacter and Addis (2007). Indeed, the "constructive episodic simulation hypothesis" of future events proposes that the simulation of future episodes requires recombining details from past events (retrospective component) into novel scenarios (prospective component). Schacter and collaborators, however, have studied the quality of past and future events. In the present work, we have added quantitative measures of past and future mental evocation (through various behavioral measures).

Phenomenological differences between past and future thinking

Although sharing a common neural network, our data show that past and future events differed phenomenologically. Past events were more episodic than future events based on the EM score. Since this score takes into account the number of phenomenological details retrieved, it indicates that past events were more detailed than future events, like reported previously in younger adults (D'Argembeau \& Van der Linden, 2004, 2006; Addis et al., 2008). Memories of past experiences contain more sensorial and contextual details than representations of the future likely due to the fact that past representations reflect real experiences, while future events are based on projections or simulations (i.e., imagination; see introduction on "reality monitoring framework"). This probably also explains why a higher state of autonoetic consciousness (based on the R/K paradigm) was observed when recalling past events compared to future events. The remembering state, reflecting autonoetic consciousness, characterizes the retrieval of specific events (for the future, it would entail that 
subjects remember thinking about their plans or are able to live future events in advance) accompanied by phenomenal elements (visual images, sensations feelings). Past events were indeed retrieved with a higher number of mental images and their quality was clearer compared to future events. Overall, although past and future events share a common neural network, they are nevertheless distinguishable at the phenomenal level, in terms of level of details, state of consciousness and number and quality of mental images.

To further investigate the episodic distinction between past and future events at the neural level, regression analyses were conducted to examine which brain region best predicted the strictly episodic score EM. For the past, results showed that EM depended on activation in the right hippocampus, posterior cingulate cortex, occipital and angular gyri. The latter regions are involved in visuo-spatial processing which promotes the retrieval of episodic autobiographical events (see introduction). The right hippocampus is particularly responsive to the sense of reliving the encoding context (Graham et al., 2003; Gilboa et al., 2004; Piolino et al., 2004, 2008; Steinvorth et al., 2006) in particular by providing the spatial context necessary to retrieve episodic memories (Burgess et al., 2002). Behaviorally, the best predictors of EM for past events were the quality of mental visual images and a field perspective, in which mental visual images represent the scene from its original point of view, indicating that the retrieval of the spatial context of past memories is critical for episodic recollection. We previously reported that the right hippocampus was recruited, in addition to its left counterpart, when retrieving phenomenologically rich episodic memories (Viard et al., 2007, 2010) requiring the integration of disparate details (see above) and the field point of view (Piolino et al., 2009). Overall, the episodic quality of past events is best explained by activity of regions implicated in recollection, either through their role in extracting the visuospatial contexts of events or in binding together disparate phenomenological elements. 
For the future, the EM score depended principally on activation in regions involved in the retrieval of semantic information, namely the left inferior frontal gyrus, previously shown to be recruited in future event construction, and the lateral temporal cortex, involved in future event elaboration (Addis et al., 2007). Behaviorally, future events were not as episodic as past events and subtraction analyses revealed higher activation within the lateral temporal cortex (involved in semantic processing) for future compared to past events. It has previously been suggested that future thinking reactivates acquired semantic knowledge (Okuda et al., 2003) or personal semantic information (Addis et al., 2007) which serve as an effective guideline to construct future events. The EM score also depended on activation in the precuneus, implicated in visual mental imagery (Cavanna and Trimble, 2006; Fletcher et al., 1995). Envisioning the visuo-spatial aspects of future events probably helped in rendering them more episodic, although they were still not as episodic as past events, as confirmed by the behavioral data.

Furthermore, subtraction analyses revealed higher activation in the posterior parietal cortex (both inferior and superior gyri) for future compared to past events (see also Addis et al., 2007). This region has been hypothesized to play a role in attentional processes, both bottom-up attention ("capture of attentional resources by relevant memory cues") via the inferior parietal gyrus and top-down attention ("allocation of attentional resources to memory retrieval according to the goals of the rememberer") via the superior parietal gyrus (Cabeza, 2008; Cabeza et al., 2008; Ciaramelli et al., 2008). It is plausible that future thinking engages higher attentional resources than past remembering in order to merge temporal projection and different types of information (personal semantic information and episodic details from distinct memory traces) and flexibly recombine them into coherent future events. Note that the conjunction analysis showed that both past and future events elicited activation in the posterior parietal cortex (inferior and superior parietal gyri). Hence, top-down and bottom-up 
attentional processes appear during past and future thinking, but they are enhanced during future thinking which requires higher attentional demands. Overall, the episodic distinction between past and future events at the behavioral level can be explained at the neuronal level by a differential recruitment of specific regions within the common core brain network underlying mental time travel into the past or the future.

\section{Conclusion}

This study showed that thinking about the past and the future recruits the same set of brains regions in healthy aged subjects reflecting the use of similar cognitive processes (visual imagery, semantic retrieval, episodic binding). When planning a future event beforehand, thinking retrospectively about it engaged the same regions as those recruited when thinking about a past event. However, past and future events differed on certain phenomenological aspects: past events were more episodic (i.e., contained more details), engaged a higher state of autonoetic consciousness and mental visual images were clearer and more numerous compared to future events. Regression analyses showed that the episodic nature of past events was particularly dependent on activation in the right hippocampus (critical in episodic recollection) and visuo-spatial areas (implicated in the retrieval of the spatial context of events), while the episodic nature of future events was dependent on the inferior frontal and lateral temporal gyri (involved in semantic retrieval). Furthermore, future events elicited greater activation in parietal regions compared to past events, reflecting the use of higher attentional resources to envision future scenarios. Although sharing common neural processes, past and future thinking differed most notably at the episodic level, likely due to the fact that past events have actually happened, while future events are mental constructions.

An obvious follow-up of the present study would be to directly compare brain activity between young and old adults during past and future thinking, to pinpoint the similarities and differences at the neural level. It would also be particularly appealing to compare future 
planning with imagination in aging, i.e. distinguish events that will really occur in the future from those that are mere figments of the imagination, to examine the impact of realness of future events on brain activity. As selective positive mental self projection into time seems to be an important part of well-being in aging (see Carstensen, Fung, Charles, 2003), future studies would be interesting to explore the specificity of the cerebral network which maintains a positive sense of ourselves as a single entity with a subjective continuity in aging despite changes. 
Viard et al.

Acknowledgements : Thanks to Dr. Alan Young for his help scanning participants and to Franck Lamberton and Nicolas Delcroix for technical support. 


\section{References}

Abraham, A., Schubotz, R.I., \& von Cramon, D.Y. (2008). Thinking about the future versus the past in personal and non-personal contexts. Brain Research, 1233, 106-119.

Addis, D.R., Wong, A.T., \& Schacter, D.L. (2007). Remembering the past and imagining the future: common and distinct neural substrates during event construction and elaboration. Neuropsychologia, 45, 1363-1377.

Addis, D.R., Wong, A.T., \& Schacter, D.L. (2008). Age-related changes in the episodic simulation of future events. Psychological Science, 19, 33-41.

Addis, D.R., Sacchetti, D.C., Ally, B.A., Budson, A.E., \& Schacter, D.L. (2009). Episodic simulation of future events is impaired in mild Alzheimer's disease. Neuropsychologia, 47, 2660-2671.

Anderson, R.J., \& Dewhurst, S.A. (2009). Remembering the past and imagining the future: differences in event specificity of spontaneously generated thought. Memory, 17, 367-373.

Andrews-Hanna, J.R., Reidler, J.S., Sepulcre, J., Poulin, R., \& Buckner, R.L. (2010). Functional-anatomic fractionation of the brain's default network. Neuron, 65, 550-562.

Ashburner, J., Friston, K.J. (2005). Unified segmentation. NeuroImage, 26, 839-851.

Atance, C.M., \& O'Neill, D.K. (2001). Episodic future thinking. Trends in Cognitive Science, 5, 533-539.

Badre, D., \& Wagner, A.D. (2007). Left ventrolateral prefrontal cortex and the cognitive control of memory. Neuropsychologia, 45, 2883-2901.

Botzung, A., Denkova, E., Manning, L. (2008). Experiencing past and future personal events: functional neuroimaging evidence on the neural bases of mental time travel. Brain and Cognition, 66, 202-212.

Brewer, W. (1986). What is autobiographical memory? In D.C. Rubin (Ed.), Autobiographical Memory (pp. 25-49). Cambridge: Cambridge University Press.

Brewer, W. (1988). Memory for randomly sampled autobiographical events. In U. Neisser \& E. Winograd (Eds.), Remembering reconsidered: ecological and traditional approaches to the study of memory (pp. 21-90). Cambridge: Cambridge University Press.

Brewer, W. (1996). What is recollective memory? In D.C. Rubin (Ed.), Remembering our past: studies in autobiographical memory (pp. 19-66). Cambridge: Cambridge University Press.

Buckner, R.L., \& Carroll, D.C. (2007). Self-projection and the brain. Trends in Cognitive Science, 11, 49-57. 
Burgess, N., Maguire, E.A., \& O'Keefe, J. (2002). The human hippocampus and spatial and episodic memory. Neuron, 35, 625-41.

Cabeza, R., \& St Jacques, P. (2007). Functional neuroimaging of autobiographical memory. Trends in Cognitive Science, 11, 219-227.

Cabeza, R. (2008). Role of parietal regions in episodic memory retrieval: the dual attentional processes hypothesis. Neuropsychologia, 46:1813-1827.

Cabeza, R., Ciaramelli, E., Olson, I.R., \& Moscovitch, M. (2008). The parietal cortex and episodic memory: an attentional account. Nature Reviews Neuroscience, 9:613-625.

Carstensen, L.L., Fung, H. \& Charles, S. (2003) Socioemotional selectivity theory and the regulation of emotion in the second half of life. Motivation and Emotion, 27, 103-123.

Cavanna, A.E., \& Trimble, M.R. (2006). The precuneus: a review of its functional anatomy and behavioural correlates. Brain, 129, 564-583.

Cermak, L.S. (1984). The episodic semantic distinction in amnesia. In L.R. Squire \& N. Butters (Eds.), The Neuropsychology of Memory (pp. 55-62). New York: The Guilford Press.

Ciaramelli, E., Grady, C.L., \& Moscovitch, M. (2008). Top-down and bottom-up attention to memory: a hypothesis (AtoM) on the role of the posterior parietal cortex in memory retrieval. Neuropsychologia, 46:1828-1851.

Conway, M.A., \& Dewhurst, S.A. (1995). Remembering, familiarity, and source monitoring. Quartely Journal of Experimental Psychology A, 48, 125-140.

Conway, M.A., Pleydell-Pearce, C.W., Whitecross, S., \& Sharpe, H. (2002). Brain imaging autobiographical memory. Psychology, Learning and Teaching, 41, 229-264.

Conway, M.A., Pleydell-Pearce, C.W., Whitecross, S.E., Sharpe, H. (2003). Neurophysiological correlates of memory for experienced and imagined events. Neuropsychologia, 41, 334-340.

Crawley, S.E., \& French, C.C. (2005). Field and observer viewpoint in remember/know memories of personal childhood events. Memory, 13, 673-681.

D'Argembeau, A., \& Van der Linden, M. (2004). Phenomenal characteristics associated with projecting oneself back into the past and forward into the future: influence of valence and temporal distance. Consciousness and Cognition, 13, 844-858.

D'Argembeau, A., \& Van der Linden, M. (2006). Individual differences in the phenomenology of mental time travel: The effect of vivid visual imagery and emotion regulation strategies. Consciousness and Cognition, 15, 342-350. 
D'Argembeau, A., Xue, G., Lu, Z.L., Van der Linden, M., \& Bechara, A. (2008). Neural correlates of envisioning emotional events in the near and far future. NeuroImage, 40, 398407.

Daselaar, S.M., Rice, H.J., Greenberg, D.L., Cabeza, R., Labar, K.S., \& Rubin, D.C. (2008). The spatiotemporal dynamics of autobiographical memory: neural correlates of recall, emotional intensity, and reliving. Cerebral Cortex, 18, 217-229.

Dewhurst, S.A., \& Conway, M.A. (1994). Pictures, images, and recollective experience. Journal of Experimental Psychology: Human Learning and Memory, 20, 1088-1098.

Dolan, R.J., Lane, R., Chua, P., \& Fletcher, P. (2000). Dissociable temporal lobe activations during emotional episodic memory retrieval. NeuroImage, 11, 203-209.

Eichenbaum, H. (2001). The hippocampus and declarative memory: cognitive mechanisms and neural codes. Behavioural Brain Research, 127, 199-207.

Fletcher, P.C., Frith, C.D., Baker, S.C., Shallice, T., Frackowiak, R.S., \& Dolan, R.J. (1995). The mind's eye-precuneus activation in memory related imagery. NeuroImage, 2, 195-200.

Gamboz, N., De Vito, S., Brandimonte, M.A., Pappalardo, S., Galeone, F., Iavarone, A., \& Della Sala, S. (2010). Episodic future thinking in amnesic mild cognitive impairment. Neuropsychologia, 48, 2091-2097.

Gamboz, N., Brandimonte, M.A., \& De Vito, S. The role of past in the simulation of autobiographical future episodes. Experimental Psychology (in press)

Gardiner, J.M. (1988). Functional aspects of recollective experience. Memory and Cognition, $16,309-313$.

Gardiner, J.M. (2001). Episodic memory and autonoetic consciousness: a first-person approach. Philosophical Transactions of the Royal Society B, 356, 1351-1361.

Gardiner, J.M., \& Java, R.I. (1993). Recognizing and remembering. In A.F. Collins, S.E. Gathercole, M.A. Conway \& P.E. Morris (Eds.), Theories of memory (pp. 163-188). Hove, England: Erlbaum.

Gardini, S., Cornoldi, C., De Beni, R., \& Venneri, A. (2006). Left mediotemporal structures mediate the retrieval of episodic autobiographical mental images. NeuroImage, 30, 645655.

Gilboa, A., Winocur, G., Grady, C.L., Hevenor, S.J., \& Moscovitch, M. (2004). Remembering our past: functional neuroanatomy of recollection of recent and very remote personal events. Cerebral Cortex, 14, 1214-1225.

Goddard, L, Pring, L., \& Felmingham, N. (2005). The effects of cue modality on the quality 
of personal memories retrieved. Memory, 13, 79-86.

Good, C.D., Johnsrude, I.S., Ashburner, J., Henson, R.N., Friston, K.J., \& Frackowiak, R.S. (2001). A voxel-based morphometric study of ageing in 465 normal adult human brains. NeuroImage, 14, 21-36.

Graham, K.S., Lee, A.C., Brett, M., \& Patterson, K. (2003). The neural basis of autobiographical and semantic memory: new evidence from three PET studies. Cognitive, Affective, and Behavioral Neuroscience, 3, 234-254.

Greenberg, D.L., \& Rubin, D.C. (2003). The neuropsychology of autobiographical memory. Cortex, 39, 687-728.

Gusnard, D.A., Akbudak, E., Shulman, G.L., \& Raichle, M.E. (2001). Medial prefrontal cortex and self-referential mental activity: relation to a default mode of brain function. Proceedings of the National Academy of Sciences of the United States of America, 98:42594264.

Hassabis, D., Kumaran, D., Vann, S.D., \& Maguire, E.A. (2007a). Patients with hippocampal amnesia cannot imagine new experiences. Proceedings of the National Academy of Sciences of the United States of America, 104, 1726-1731.

Hassabis, D., Kumaran, D., \& Maguire, E.A. (2007b). Using imagination to understand the neural basis of episodic memory. Journal of Neuroscience, 27, 14365-14374.

Hassabis, D., \& Maguire, E.A. (2007). Deconstructing episodic memory with construction. Trends in Cognitive Science, 11, 299-306.

Hassabis, D., \& Maguire, E.A. (2009). The construction system of the brain. Philosophical Transactions of the Royal Society of London B Biological Sciences, 364, 1263-1271.

Johnson, M.K., \& Raye, C.L. (1981). Reality monitoring. Psychological Review, 88, 67-85.

Johnson, M.K. (1991). Reflection, reality monitoring, and the self. In R. Kunzendorf (Ed.) Mental imagery (pp. 3-16). New York: Plenum.

Kelley, W.M., Macrae, C.N., Wyland, C.L., Caglar, S., Inati, S., \& Heatherton, T.F. (2002). Finding the self? An event-related fMRI study. Journal of Cognitive Neuroscience, 14, 785794.

Klein, S.B., Loftus, J., \& Kihlstrom, J. (2002). Memory and temporal experience. The effects of episodic memory loss on an amnesic patient's ability to remember the past and imagine the future. Social Cognition, 20, 353-379.

Levine, B., 2004. Autobiographical memory and the self in time: brain lesion effects, functional neuroanatomy, and lifespan development. Brain and Cognition, 55, 54-68. 
Libby, L.K., \& Eibach, R.P. (2002). Looking back in time: Self-concept change affects visual perspective in autobiographical memory. Journal Of Personality And Social Psychology, $82,167-179$.

Linton, M. (1986). Ways of searching and the contents of memory. In D.C. Rubin (Ed.), Autobiographical Memory (pp. 50-67). Cambridge: Cambridge University Press.

Linton, M. (1988). The maintenance of knowledge: some long-term specific and generic changes. In M.M. Gruneberg, P.E. Morris \& R.N. Sykes (Eds.), Practical aspects of memory (pp. 378-384). London: Wiley.

Maguire, E.A. (2001). Neuroimaging studies of autobiographical event memory. Philosophical Transactions of the Royal Society of London B Biological Sciences, 356, 1441-1451.

Maguire, E.A., \& Frith, C.D. (2003). Aging affects the engagement of the hippocampus during autobiographical memory retrieval. Brain, 126, 1511-1523.

Nadel, L., Campbell, J., \& Ryan, L. (2007). Autobiographical memory retrieval and hippocampal activation as a function of repetition and the passage of time. Neural Plasticity, 2007, 90472.

Nichols, T., Brett, M., Andersson, J., Wager, T., \& Poline, J.B. (2005). Valid conjunction inference with the minimum statistic. NeuroImage, 25, 653-660.

Nigro, G., \& Neisser, U. (1983). Point of view in personal memories. Cognitive Psychology, $15,467-482$.

Northoff, G., \& Bermpohl, F. (2004). Cortical midline structures and the self. Trends in Cognitive Science, 8, 102-107.

Okuda, J., Fujii, T., Ohtake, H., Tsukiura, T., Tanji, K., Suzuki, K., Kawashima, R., Fukuda, H., Itoh, M., \& Yamadori, A. (2003). Thinking of the future and past: the roles of the frontal pole and the medial temporal lobes. NeuroImage, 19, 1369-1380.

Peters, J., \& Büchel, C. (2010). Episodic future thinking reduces reward delay discounting through an enhancement of prefrontal-mediotemporal interactions. Neuron, 66, 138-148.

Petrides, M. (2002). The mid-ventrolateral prefrontal cortex and active mnemonic retrieval. Neurobiology of Learning and Memory, 78, 528-538.

Piefke, M., \& Fink, G.R. (2005). Recollections of one's own past: the effects of aging and gender on the neural mechanisms of episodic autobiographical memory. Anatomy and Embryology, 210, 497-512.

Piolino, P., Desgranges, B., Clarys, D., Guillery-Girard, B., Taconnat, L., Isingrini, M., \& 
Eustache, F. (2006). Autobiographical memory, autonoetic consciousness, and selfperspective in aging. Psychology and Aging, 21, 510-525.

Piolino, P., Desgranges, B., \& Eustache, F. (2009). Episodic autobiographical memories over the course of time: cognitive, neuropsychological and neuroimaging findings. Neuropsychologia, 47, 2314-2329.

Piolino, P., Desgranges, B., Hubert, V., Bernard, F., Chételat, G., Baron, J.C., \& Eustache, F. (2008). Reliving lifelong episodic autobiographical memories via the hippocampus: A correlative resting PET study in healthy middle-aged subjects. Hippocampus, 18, 445-459.

Piolino, P., Giffard-Quillon, G., Desgranges, B., Chételat, G., Baron, J.C., \& Eustache, F. (2004). Re-experiencing old memories via hippocampus: a PET study of autobiographical memory. NeuroImage, 22, 1371-1383.

Raposo, A., Han, S., \& Dobbins, I.G. (2009). Ventrolateral prefrontal cortex and selfinitiated semantic elaboration during memory retrieval. Neuropsychologia, 47, 2261-2271.

Rekkas, P.V., \& Constable, R.T. (2005). Evidence that autobiographic memory retrieval does not become independent of the hippocampus: an fMRI study contrasting very recent with remote events. Journal of Cognitive Neuroscience, 17, 1950-1961.

Rubin, D.C., Schrauf, R.W., \& Greenberg, D.L. (2003). Belief and recollection of autobiographical memories. Memory and Cognition, 31, 887-901.

Schacter, D.L., \& Addis, D.R. (2007). The cognitive neuroscience of constructive memory: remembering the past and imagining the future. Philosophical Transactions of the Royal Society of London B Biological Sciences, 362, 773-786.

Sharot, T., Riccardi, A.M., Raio, C.M., \& Phelps, E.A. (2007). Neural mechanisms mediating optimism bias. Nature, 450, 102-105.

Spreng, R.N., \& Grady, C.L. (2010). Patterns of Brain Activity Supporting Autobiographical Memory, Prospection, and Theory-of-Mind and Their Relationship to the Default Mode Network. Journal of Cognitive Neuroscience, 22, 1112-23.

Spreng, R.N., \& Levine, B. (2006). The temporal distribution of past and future autobiographical events across the lifespan. Memory and Cognition, 34, 1644-1651.

Steinvorth, S., Corkin, S., \& Halgren, E. (2006). Ecphory of autobiographical memories: an fMRI study of recent and remote memory retrieval. NeuroImage, 30, 285-298.

Svoboda, E., McKinnon, M.C., \& Levine, B. (2006). The functional neuroanatomy of autobiographical memory: a meta-analysis. Neuropsychologia, 44, 2189-2208.

Szpunar, K.K., Chan, J.C., \& McDermott, K.B. (2009). Contextual processing in episodic 
future thought. Cerebral Cortex, 19, 1539-1548.

Szpunar, K.K., Watson, J.M., \& McDermott, K.B. (2007). Neural substrates of envisioning the future. Proceedings of the National Academy of Sciences of the United States of America, 104, 642-647.

Tulving, E. (1985). Memory and consciousness. Canadian Psychologist, 26, 1-12.

Tulving, E. (2002). Chronestesia: Conscious Awareness of Subjective Time. In D.T. Stuss, \& R.C. Knight (Eds.), Principles of Frontal Lobe Functions (pp. 311-325). New York: Oxford University Press.

Tulving, E. (2005). Episodic memory and autonoesis: Uniquely human? In H.S. Terrace \& J. Metcalfe (Eds.), The missing link in cognition: Origins of self-reflective consciousness (pp. 3-56). New York: Oxford University Press.

Viard, A., Piolino, P., Desgranges, B., Chételat, G., Lebreton, K., Landeau, B., Young, A., De La Sayette, V., \& Eustache, F. (2007). Hippocampal activation for autobiographical memories over the entire lifetime in healthy aged subjects: An fMRI study. Cerebral Cortex, 17, 2453-2467.

Viard, A., Lebreton, K., Chételat, G., Desgranges, B., Landeau, B., Young, A., De La Sayette, V., Eustache, F., \& Piolino, P. (2010). Patterns of hippocampal-neocortical interactions in the retrieval of episodic autobiographical memories across the entire lifespan of aged adults. Hippocampus, 20, 153-165.

Weiler, J.A., Suchan, B., \& Daum, I. (2010). Foreseeing the future: Occurrence probability of imagined future events modulates hippocampal activation. Hippocampus, 20, 685-90.

Wheeler, M.A., Stuss, D.T., \& Tulving, E. (1997). Toward a theory of episodic memory: the frontal lobes and autonoetic consciousness. Psychological Bulletin, 121, 331-354. 
Table 1: Behavioral results of the ANOVA applied on all behavioral scores for the past and future periods (mean \pm S.D.) and post hoc analyses [PLSD Fisher tests] showing the effect of time-period.

\begin{tabular}{l|c|c|c} 
Behavioral score & Past & Future & p \\
\hline EM & $0.80( \pm 0.27)$ & $0.43( \pm 0.33)$ & $0.0086^{*}$ \\
Frequency of rehearsal & $5.51( \pm 1.99)$ & $4.11( \pm 2.55)$ & $\mathrm{ns}$ \\
Last evocation & $1.67( \pm 0.91)$ & $1.63( \pm 1.45)$ & $\mathrm{ns}$ \\
Emotional intensity at retrieval & $5.09( \pm 1.59)$ & $4.46( \pm 1.97)$ & $\mathrm{ns}$ \\
Emotional valence at retrieval & $6.57( \pm 1.26)$ & $6.72( \pm 0.89)$ & $\mathrm{ns}$ \\
State of consciousness & $* *$ \\
Mental strategy used & $9.23( \pm 0.69)$ & $6.28( \pm 3.47)$ & $0.038^{*}$ \\
Mental visual image quality & $9.13( \pm 1.25)$ & $7.55( \pm 1.56)$ & $0.0013^{*}$ \\
$\begin{array}{l}\text { Number of mental visual } \\
\text { images }\end{array}$ & $5.06( \pm 2.12)$ & $3.17( \pm 1.52)$ & $0.0005^{*}$ \\
Point of view & $1.40( \pm 0.59)$ & $1.14( \pm 0.77)$ & $\mathrm{ns}$
\end{tabular}

* post hoc analyses indicate that Past $>$ Future

$* * \mathrm{~N}=8$

Abbreviations: $\mathrm{EM}=$ strictly episodic score; $\mathrm{ns}=$ non significant.

EM is expressed in terms of ratio of strictly episodic memories per period (i.e., number of strictly episodic memories divided by the number of memories). Analogical scales range from 0 to 10 for the frequency of rehearsal $(0=$ never to $10=$ very frequent $)$, last evocation $(0=$ today to $10=$ over 10 years ago $)$, emotional intensity at retrieval $(0=$ no emotion to $10=$ very strong emotion), emotional valence at retrieval $(0=$ very negative to $10=$ very positive $)$, state of consciousness $(0=$ knowing to $10=$ remembering $)$, mental strategy used $(0=$ verbal to 10 $=$ visual $)$, number of mental visual images $(0=$ no images to $10=$ over 10 images $)$, mental 
Viard et al.

visual image quality $(0=$ very blurry to $10=$ very clear. For the point of view, the maximum score is $2(0=$ observer; $1=$ field and observer; $2=$ field $)$. 
Table 2: Results of the conjunction analysis, specifying for each peak the Brodmann area(s) (BA), side, cluster size (k), Z score, and MNI coordinates (x y z) at $\mathrm{p}_{\text {unc }}<0.001$, cluster-level $\mathrm{k}>15$ voxels.

\begin{tabular}{|c|c|c|c|c|c|c|c|}
\hline Regions & $\mathbf{B A}$ & Side & $\mathbf{k}$ & Z score & $\mathbf{x}$ & $\mathbf{y}$ & $\mathbf{z}$ \\
\hline \multirow{3}{*}{ PCC/precuneus } & 23 & $\mathrm{~L}$ & 3880 & 6.18 & -16 & -58 & 14 \\
\hline & 30 & $\mathrm{R}$ & & 5.27 & 8 & -52 & 12 \\
\hline & 7 & $\mathrm{~L}$ & & 5.20 & -2 & -64 & 42 \\
\hline \multirow[t]{5}{*}{ Middle frontal gyrus } & 8 & $\mathrm{~L}$ & 1273 & 5.64 & -36 & 10 & 46 \\
\hline & 6 & $\mathrm{~L}$ & & 4.83 & -36 & 18 & 54 \\
\hline & 6 & $\mathrm{~L}$ & & 4.63 & 2 & 12 & 50 \\
\hline & 6 & $\mathrm{R}$ & 32 & 3.68 & 32 & 16 & 52 \\
\hline & 9 & $\mathrm{R}$ & 17 & 3.49 & 34 & 8 & 36 \\
\hline \multirow[t]{2}{*}{ Superior frontal gyrus } & 8 & $\mathrm{~L}$ & 57 & 4.16 & -18 & 40 & 50 \\
\hline & 8 & $\mathrm{R}$ & 13 & 3.70 & 26 & 50 & 38 \\
\hline \multirow[t]{2}{*}{ Superior medial frontal gyrus } & $8 / 32$ & $\mathrm{~L}$ & 40 & $3.54 *$ & -12 & 26 & 34 \\
\hline & 10 & $\mathrm{~L}$ & 23 & $3.00 *$ & -16 & 54 & 20 \\
\hline \multirow[t]{2}{*}{ Inferior frontal gyrus } & 47 & $\mathrm{~L}$ & 32 & 3.48 & -38 & 26 & -12 \\
\hline & 47 & $\mathrm{R}$ & 15 & 3.45 & 36 & 38 & -4 \\
\hline \multirow[t]{2}{*}{ Angular gyrus } & 39 & $\mathrm{R}$ & 386 & 5.28 & 46 & -72 & 36 \\
\hline & 39 & $\mathrm{~L}$ & 747 & 4.95 & -46 & -66 & 32 \\
\hline \multirow[t]{2}{*}{ Superior temporal gyrus } & 38 & $\mathrm{R}$ & 24 & 4.55 & 58 & -6 & -10 \\
\hline & 22 & $\mathrm{R}$ & 23 & 3.50 & 44 & -36 & 4 \\
\hline Middle temporal gyrus & 21 & $\mathrm{~L}$ & 152 & 4.12 & -60 & -10 & -8 \\
\hline Fusiform gyrus & 36 & $\mathrm{~L}$ & 35 & 5.18 & -38 & -60 & -22 \\
\hline \multirow[t]{2}{*}{ Hippocampus } & & $\mathrm{L}$ & 17 & 3.62 & -14 & -20 & -12 \\
\hline & & $\mathrm{R}$ & 13 & $3.21 *$ & 16 & -18 & -12 \\
\hline Parahippocampal gyrus & 36 & $\mathrm{~L}$ & 17 & 3.51 & -22 & -38 & -12 \\
\hline Cerebellum & & $\mathrm{R}$ & 916 & 6.46 & 16 & -78 & -16 \\
\hline Vermis & & $\mathrm{L}$ & & 5.63 & -2 & -76 & -18 \\
\hline Cerebellum & & $\mathrm{R}$ & 46 & 4.15 & 36 & -58 & -24 \\
\hline Thalamus & & $\mathrm{L}$ & 21 & 4.01 & -2 & -16 & -2 \\
\hline
\end{tabular}


Viard et al.

$\begin{array}{llllllll} & & \mathrm{R} & & 3.20 & 2 & -20 & -10 \\ \text { Calcarine sulcus } & 17 & \mathrm{~L} & 20 & 3.71 & -8 & -82 & 10\end{array}$

$* \mathrm{p}_{\text {unc }}<0.005$

Abbreviations: PCC: posterior cingulate cortex 
Table 3 : Results of the subtraction analysis (Future > Past), specifying for each peak the Brodmann area(s) (BA), side, cluster size (k), Z score, and MNI coordinates (x y z) at $\mathrm{p}_{\text {unc }}<$ 0.001 , cluster-level $\mathrm{k}>15$ voxels.

\begin{tabular}{lccccccc} 
Regions & BA & Side & $\mathbf{k}$ & $\mathbf{Z}$ score & $\mathbf{x}$ & $\mathbf{y}$ & $\mathbf{z}$ \\
\hline Inferior parietal gyrus & 40 & $\mathrm{~L}$ & 101 & 4.83 & -48 & -56 & 42 \\
Angular gyrus & 39 & $\mathrm{~L}$ & & 3.66 & -54 & -54 & 32 \\
Cerebellum & & $\mathrm{R}$ & 29 & 4.11 & 16 & -78 & -16 \\
Fusiform gyrus & 19 & $\mathrm{R}$ & & 3.29 & 28 & -78 & -6 \\
Vermis & & $\mathrm{R}$ & 25 & 3.76 & 0 & -74 & -12 \\
Lingual gyrus & 18 & $\mathrm{R}$ & & 3.47 & 8 & -76 & -10 \\
Superior parietal gyrus & 7 & $\mathrm{~L}$ & 25 & 3.62 & -22 & -72 & 58 \\
Middle temporal gyrus & $37 / 21$ & $\mathrm{R}$ & 11 & 3.39 & 44 & -66 & 6 \\
Cuneus & 19 & $\mathrm{R}$ & 11 & 3.42 & 22 & -56 & 36
\end{tabular}


Table 4: Results of the regression analyses between the EM score and brain activation values, for the past and future periods, specifying the Brodmann area(s) (BA), side, cluster size (k), Z score, and MNI coordinates (x y z) at $\mathrm{p}_{\mathrm{unc}}<0.005, \mathrm{k}>15$ voxels.

\begin{tabular}{|c|c|c|c|c|c|c|c|c|}
\hline & Regions & $\mathbf{B A}$ & Side & $\mathbf{k}$ & $Z$ score & $\mathbf{x}$ & $\mathbf{y}$ & $\mathbf{z}$ \\
\hline \multirow{6}{*}{$\begin{array}{l}\text { EM } \\
\text { Past }\end{array}$} & Middle occipital gyrus & 19 & $\mathrm{R}$ & 58 & 4.70 & 52 & -70 & 24 \\
\hline & Hippocampus & & $\mathrm{R}$ & 120 & 3.25 & 30 & -38 & -4 \\
\hline & Angular gyrus & 39 & $\mathrm{~L}$ & 74 & 3.24 & -42 & -66 & 26 \\
\hline & PCC & 30 & $\mathrm{~L}$ & 35 & 3.07 & -12 & -56 & 12 \\
\hline & Thalamus & & $\mathrm{R}$ & 15 & 3.02 & 18 & -18 & 6 \\
\hline & Insula & & $\mathrm{L}$ & 23 & 3.00 & -32 & -16 & 18 \\
\hline EM & Inferior frontal gyrus & 45 & $\mathrm{~L}$ & 94 & 3.58 & -46 & 24 & 14 \\
\hline \multirow[t]{7}{*}{ Future } & & 44 & $\mathrm{~L}$ & & 3.28 & -50 & 10 & 8 \\
\hline & & 44 & $\mathrm{~L}$ & & 2.95 & -42 & 14 & 8 \\
\hline & Superior temporal gyrus & 42 & $\mathrm{R}$ & 69 & 3.37 & 44 & -22 & 10 \\
\hline & & 21 & $\mathrm{R}$ & & 3.30 & 48 & -18 & 2 \\
\hline & & 22 & $\mathrm{~L}$ & 22 & 2.98 & -46 & -14 & 2 \\
\hline & Precuneus & 31 & $\mathrm{R}$ & 20 & 2.88 & 22 & -62 & 24 \\
\hline & Thalamus & & $\mathrm{R}$ & 16 & 3.02 & 14 & -18 & 16 \\
\hline
\end{tabular}

Abbreviations: PCC: posterior cingulate cortex 
Figure 1: Statistical parametric maps depicting the results of the conjunction analysis showing regions commonly active for past and future periods. Stereotaxic coordinates are given on Table 2. For representational purposes, the coronal slice (far right) is thresholded at $\mathrm{p}_{\text {unc }}<0.005$ to depict the bilateral hippocampal activation.

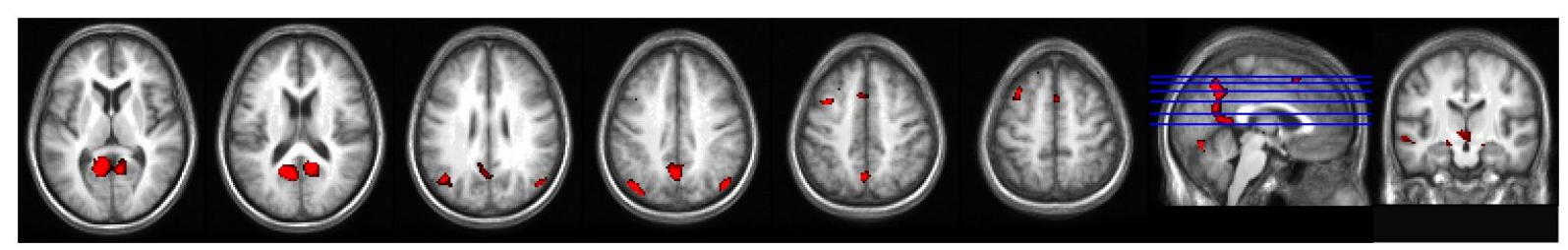

